\title{
Secreted Frizzled Related Protein 2 (sFRP2) decreases susceptibility to UV-induced apoptosis in primary culture of canine mammary gland tumors by NF- $\kappa$ B activation or JNK suppression
}

\author{
Jia-Lin Lee $\cdot$ Ching-Jin Chang $\cdot$ Ling-Ling Chueh • \\ Chung-Tien Lin
}

Received: 14 March 2006/Accepted: 15 March 2006/Published online: 22 June 2006

(C) Springer Science+Business Media B.V. 2006

\begin{abstract}
Tumor formation can result from a decrease in cell death, as well as an increase in cell proliferation. In spite of the high incidence of mammary gland tumors (MGTs) in female dogs, the understanding of its etiology is still poor. Consistent with several proto-oncogenes (such as Wnt) for the mammary gland, sFRP2 is expressed in canine MGTs which is normally silent in the mammary gland. To elucidate the roles of SFRP2 in the tumorigenesis of MGTs, apoptosis regulation mediated by sFRP2 was investigated by overexpression of sFRP2 in MGT cells. DNA fragmentation and TUNEL assays showed a decreased susceptibility of the cells to UV-induced apoptosis in the context of sFRP2 overexpression. To analyze the pathways through which sFRP2 transduces anti-apoptosis signals, multiple-color immunofluorescence staining, immunoprecipitation, and immunoblotting were carried out. SFRP2 was found co-localized in the extracellular matrix of MGTs and the tyrosine phosphorylation of FAK was enhanced. Moreover, JNK was suppressed and NF-kB was activated in the cells expressing sFRP2 after UV-induced apoptosis analyzed by immunoblotting and electrophoretic mobility shift assay (EMSA). Taken together,
\end{abstract}

The first two authors contributed equally.

J.-L. Lee · L.-L. Chueh · C.-T. Lin $(\bowtie)$

Department and Graduate Institute of Veterinary Medicine, College of Bio-resources and Agriculture, National Taiwan University, No. 1, Section 4, Roosevelt Road, Taipei 106,

Taiwan

e-mail: ctlin@ntu.edu.tw

C.-J. Chang

Institute of Biological Chemistry, Academia Sinica, Taipei,

Taiwan these results suggest that sFRP2 exerts its anti-apoptotic function in mammary cancer cells through $\mathrm{NF}-\kappa \mathrm{B}$ activation or JNK suppression.

Keywords Secreted frizzled related protein $2 \cdot \mathrm{sFRP} 2$. Wnt signaling $\cdot$ Mammary gland tumor $\cdot$ Apoptosis ·

FAK $\cdot$ JNK $\cdot$ NF-kB $\cdot$ Dog

\section{Introduction}

The ability of tumor cell populations to expand in number is determined not only by the rate of cell proliferation but also by the rate of cell attrition. Apoptosis represents a major source of this attrition. Altering components of the apoptotic machinery can dramatically affect the dynamics of tumor progression, providing a rationale for the inactivation of this machinery during tumor development, especially in breast cancer [1]. Recently the results of several studies suggest that upregulated cell proliferation or downregulated apoptosis may allow the accumulation of mutations resulting in subsequent development of breast cancer [2]. Thus, a defect in apoptosis may be involved in aberrant survival, the development of breast cancer or both, and deregulation of apoptosis may be involved in the development of breast cancer by the enhancement of cell survival and development of drug resistance by breast cancer cells [2].

The Wnt signaling networks influence biological processes ranging from developmental cell fate, cell polarity and adhesion, tumorigenesis, and apoptosis [3-5]. The first Wht gene (previously known as Int-1) was initially identified as an oncogene frequently involved in mouse mam- 
mary tumors [6-8]. Several other Wnt family members are expressed in human breast tissue, and some are overexpressed in breast tumors [9]. Related to the Wnt-signaling cascade, a large family of secreted frizzled-related proteins (SFRPs) has recently been identified in a wide variety of organisms including Xenopus, mouse, rat, and human [1013]. There are seven SFRPs that have been identified to date [14]. This protein contains a cysteine-rich domain (CRD) which is homologous to the putative Wnt-binding domain, but lacks the transmembrane domain of frizzled proteins [12]. SFRPs are expressed in many cell types during embryogenesis [15-16] and participate in modulating Wnt-frizzled signaling [11] and apoptosis [17-18]. Some disease circumstances where SFRPs have shown increased expression are those associated with increased cell death, particularly those where apoptosis is occurring. In overload-induced heart failure, the mRNA levels of proapoptotic SFRP3 and SFRP4, but not of SFRP1 and SFRP2 were elevated in failing ventricles compared with control donor hearts [19]. In degenerative human retinal disease, in which photoreceptor neurons apparently die apoptotically, SFRPs mRNA and protein expression was strikingly elevated, although there was idiosyncratic variation in the levels for each of the SFRPs detected [20-21].

In our study on the tumorigenesis of canine mammary gland tumors (MGTs), we have found that a member of SFRP family, SFRP2, is highly induced in canine MGTs [22]. SFRP2 can serve as a modulator of Wnt signaling and is involved in development, apoptosis regulation and cancer progression [3, 18, 22, 24]. SFRP2 in the eye is potentially in influencing retinal cell survival. SFRP2 upregulation in the retinas of retinitis pigmentosa may reflect an anti-apoptotic response [20]. Overexpression of transfected SFRP2 in breast adenocarcinoma cells increased their resistance to apoptotic signals and was associated with increased intracellular levels of $\beta$-catenin [17].

The SFRP2 mediated anti-apoptosis signaling pathways are currently unknown. To gain insight into mechanisms of SFRP2-mediated anti-apoptosis, we undertook expression profiling to identify further differentially expressed apoptotic genes in MGTs using a model of canine MGT primary culture. We have demonstrated that SFRP2 decreases susceptibility to UV-induced apoptosis in primary culture of canine MGTs by NF- $\kappa \mathrm{B}$ activation or JNK suppression.

\section{Materials and methods}

Primary culture from canine MGTs

Surgically resected specimens (tubular carcinoma from a 12-year-old female dog and normal mammary glands from a 12-year-old female dog) were collected from the freshly excised tissues. Primary culture was prepared by a mechanical technique in stead of enzymatic digestion as previously described [24]. After agar and dilution cloning, purified cancer cells were plated at $25 \mathrm{~T}$ flask and incubated at $37^{\circ} \mathrm{C}$ in a humidified atmosphere of $5 \% \mathrm{CO}_{2}$ in air. Cancer cells were grown in Dulbecco's modified Eagle's (DME) culture medium supplemented with $10 \%$ fetal bovine serum (FBS). The cells were subcultured at subconfluency by harvesting with $0.05 \%$ trypsin-EDTA. The cells of primary culture were positive for cytokeratin 8,18 to make sure that they were not fibroblast. The primary culture was termed as "MPG".

\section{Expression plasmids and antibodies}

Canine homologue of sFRP2 cDNA was first isolated and cloned from a retina-specifically expressed gene population of a subtractive canine retinal cDNA library [25-26]. Fulllength canine sFRP2 cDNA was subcloned into the mammalian expression vector pcDNA4 (InVitrogen), where sFRP2 is under control of the CMV promoter and recombination can be selected by neomycin resistance. The rabbit polyclonal sFRP2, anti-NF- $\kappa \mathrm{B}$, anti-JNK1, mouse monoclonal anti-phospho-JNK, rhodamine-conjugated donkey anti-mouse IgG, and FITC-conjugated donkey anti-rabbit IgG antibodies were purchased from Santa Cruz Biotechnology. The mouse monoclonal anti-FAK and anti-phosphotyrosine antibodies were purchased form Transduction Laboratories. The mouse monoclonal anti-FN antibodies were purchased form Chemicon.

Cell culture and stably transfected cells lines

MPG cells were maintained in DMEM supplemented with $10 \%$ FBS. The cells were transfected using the Lipofectamine plus reagent (Life Technologies) according to the manufacturer's instructions. After selection by G418 $(1.0 \mathrm{mg} / \mathrm{ml})$, the transfected cells were cloned by limited dilution. The clones expressing GFP-fused SFRP2 were expanded and maintained in DMEM containing 10\% FBS and G418 $(20 \mathrm{mg} / \mathrm{ml})$.

\section{UV irradiation and DNA laddering assays}

For UV irradiation, cells were plated at $60-\mathrm{mm}$ culture dish in growth media. The medium was reduced to $1 \mathrm{ml} / \mathrm{dish}$, and the culture dishes were uncovered and exposed in an UV cross-linker (model HL-2000, UVP Laboratory Products) as previously described $[18,27]$. UV irradiation was carried out with $50,100,200 \mathrm{~J} / \mathrm{m}^{2}$. Following irradiation, $3 \mathrm{ml}$ of growth medium was added and the cells were incubated at $37^{\circ} \mathrm{C}$ in a $\mathrm{CO}_{2}$ incubator. Apoptosis was determined by DNA fragmentation assays. After $24 \mathrm{~h}$ of 
incubation, the medium of cells was collected and added to the scraped cells to allow centrifugation of both adhering and floating cells. The details of DNA laddering assays were performed essentially as described [18, 28].

In situ DNA degradation assay by terminal nucleotidyl transferase-mediated UTP nick end labeling (TUNEL) staining reaction

DNA fragmentation analysis of individual cell was performed by DNA nicked-end labeling using terminal- $d$ transferase. After $24 \mathrm{~h}$ of $200 \mathrm{~J} / \mathrm{m}^{2} \mathrm{UV}$ irradiation, cells were fixed using cold $4 \%$ paraformaldehyde in PBS for 10 min. Fixed cells were rinsed twice with PBS. The cells were performed using the DeadEnd ${ }^{\mathrm{TM}}$ Colorimetric TUNEL System reagent (Promega) according to the manufacturer's instructions. Cells were then covered with terminal transferase reaction buffer (including TdT enzyme and biotinylated nucleotide mix). The reaction was performed at $37^{\circ} \mathrm{C}$ for $1 \mathrm{~h}$ in a humidified chamber and then terminated by transferring to a TB buffer for $15 \mathrm{~min}$ at room temperature. The specimens were then rinsed in double distilled water and incubated in $2 \%$ bovine serum albumin for $10 \mathrm{~min}$. After the addition of serum albumin, the specimens were incubated with streptavidin HRP in PBS for $30 \mathrm{~min}$ at room temperature and subsequently washed twice in PBS. Color development of the cells was performed by incubation with DAB chromogen solution containing hydrogen peroxide. The percentage of apoptotic cells was determined by counting 1000 cells.

Multiple-color immunofluorescence staining

To examine the distribution of fibronectin and sFRP2 expression, paraffin-embedded sections of MGTs were stained with a variety of antibodies. In brief, tissue sections were blocked with 5\% normal donkey serum. Double antibody immunofluorescence was performed by incubating slides for $1 \mathrm{~h}$ at $37^{\circ} \mathrm{C}$ with PBS containing the mouse monoclonal anti-fibronectin antibodies. After washing with PBS, slides were incubated for $30 \mathrm{~min}$ at $37^{\circ} \mathrm{C}$ with $\mathrm{PBS}$ containing rhodamine-conjugated donkey anti-mouse IgG. Slides were then washed and incubated for a further $1 \mathrm{~h}$ at $37^{\circ} \mathrm{C}$ with PBS containing the rabbit polyclonal sFRP2 antibodies followed by incubation with FITC-conjugated donkey anti-rabbit IgG. At the end of the staining, slides were washed and incubated with 4',6-diamidino-2 phenylindole (DAPI) for nuclear staining.

Protein preparation, immunoprecipitation and immunoblotting

After $24 \mathrm{~h}$ of $200 \mathrm{~J} / \mathrm{m}^{2} \mathrm{UV}$ irradiation, cells were washed with PBS and scraped into $100 \mathrm{ml}$ RIPA lysis buffer. For experiments of FAK activities, cells were pre-incubated with $10 \mathrm{ng} / \mu \mathrm{l}$ of fibronectin (Invitrogen) for 10, 20, 30, $90 \mathrm{~min}$ at $37^{\circ} \mathrm{C}$ in a $5 \% \mathrm{CO}_{2}$ atmosphere. The details of immunoprecipitation and immunoblotting were performed essentially as described [18, 29]. The protein concentration of each sample was determined using a protein assay kit (Bio-Rad Laboratories). An equal amount of proteins was resolved by SDS-polyacrylamide gel electrophoresis and analyzed by immunoblotting with anti-JNK or anti-phospho-JNK antibodies using the Amersham Pharmacia Biotech chemiluminescence system for staining detection.

Preparation of nuclear extracts and quantitation of NF- $\kappa \mathrm{B}{ }^{32} \mathrm{P}$-DNA-binding activity

The nuclear fraction of cells was performed as described previously [30]. The DNA-binding activity of NF-kB was determined by electrophoretic mobility shift assay (EMSA) as described previously [30]. The $\left[{ }^{32} \mathrm{P}\right] \mathrm{DNA}-$ protein complex was identified as a retarded radioactive band in EMSA detected by autoradiography. This was characterized by competition experiments with nonradioactive wild-type $\mathrm{NF}-\kappa \mathrm{B}$ oligonucleotide and by interaction with anti-p50 antibodies that caused a supershift of the ${ }^{32} \mathrm{P}-$ DNA-NF- $\kappa$ B complex.

Statistical analysis

Data are expressed as means from 3 independent experiments. Statistical analysis was performed by Student $t$-test. $P<0.05$ was considered statistically significant.

\section{Results}

Overexpression of sFRP2 results in a decreased sensitivity to UV-induced apoptosis

Previously sFRP2 has been reported to possess anti-apoptosis activity $[17,18]$. To explore the molecular mechanisms underlying the anti-apoptosis effect of sFRP2 in mammary tissues, vectors encoding full-length sFRP2 were constructed and delivered into MPG cells. After being selected by G418, the stable clones of MPG/pcDNA4-pGFP and MPG/pcDNA4-pGFP-csFRP2 were collected and the percentage of cells expressing GFP or GFP-csFRP2 fusion proteins was determined by fluorescence microscope. The MPG cells expressing GFP are shown in the Fig. 1A-a, b. The MPG cells expressing GFP-csFRP2 fusion protein are shown in the Fig. 1A-c, d. To further examine the functional activity of sFRP2, the stably transfected cells described in the Fig. 1A were exposed to UV and subjected to DNA fragmentation analysis. Figure. 1B shows that over- 
Fig. 1 Cell culture and stably transfected cells lines. (A) MPG cells were transfected with expression vectors for $\mathrm{sFRP} 2$ proteins (pcDNA4-pGFPcsFRP2) or the vector backbone (pcDNA4-pGFP) and selected by G418. The percentage of cells expressing GFP or GFPcsFRP2 fusion proteins was determined by fluorescence microscope. (a, b) MPG/ pcDNA4-pGFP cells. (c, d) MPG/ pcDNA4-pGFP-csFRP2 cells. Original magnification: top panel, X40; bottom panel, X200. (B) DNA fragmentation assay. The same cells as in $\mathbf{A}$ were irradiated with UV at 50 , $100,200 \mathrm{~J} / \mathrm{m}^{2} .24$ hours after irradiation, the cells were analyzed for DNA

fragmentation by DNA laddering. (C) TUNEL assay. The same cells as in $\mathbf{A}$ were irradiated with UV at $200 \mathrm{~J} / \mathrm{m}^{2}$. 24 hours after irradiation, the cells were analyzed for DNA fragmentation by in situ DNA degradation assay (TUNEL) staining. The percentage of apoptotic cells was determined by counting 1000 cells. Results represent the means \pm SE of three independent experiments. **: $P<0.05$
A
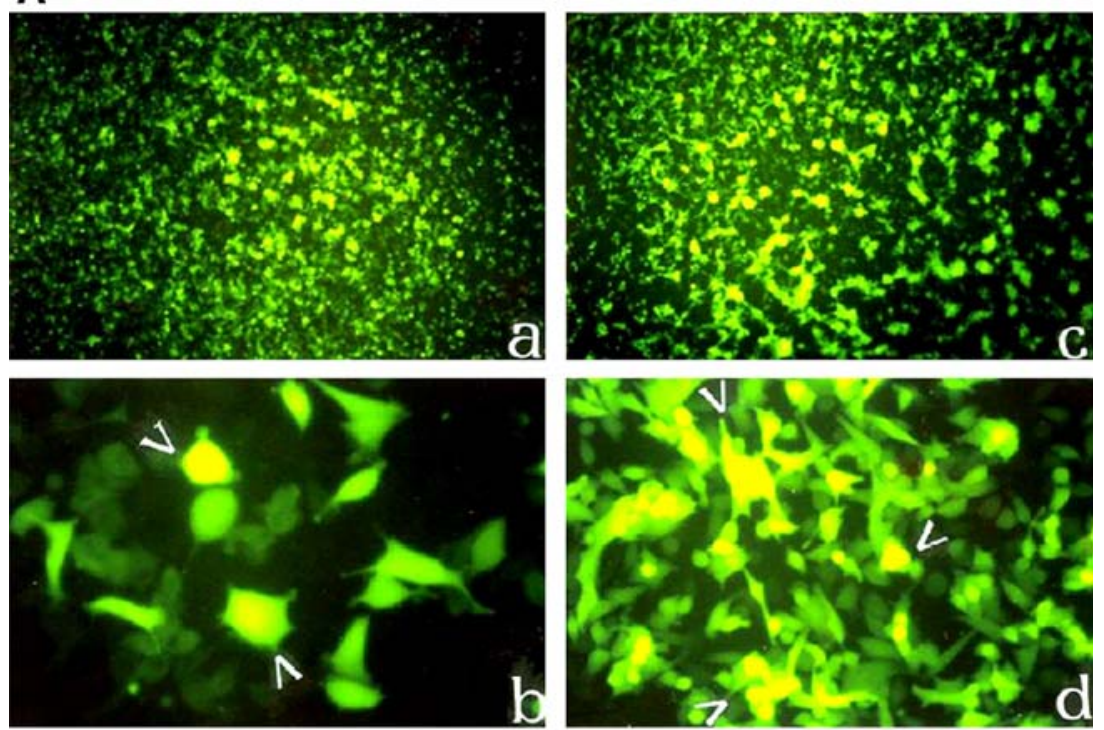

B
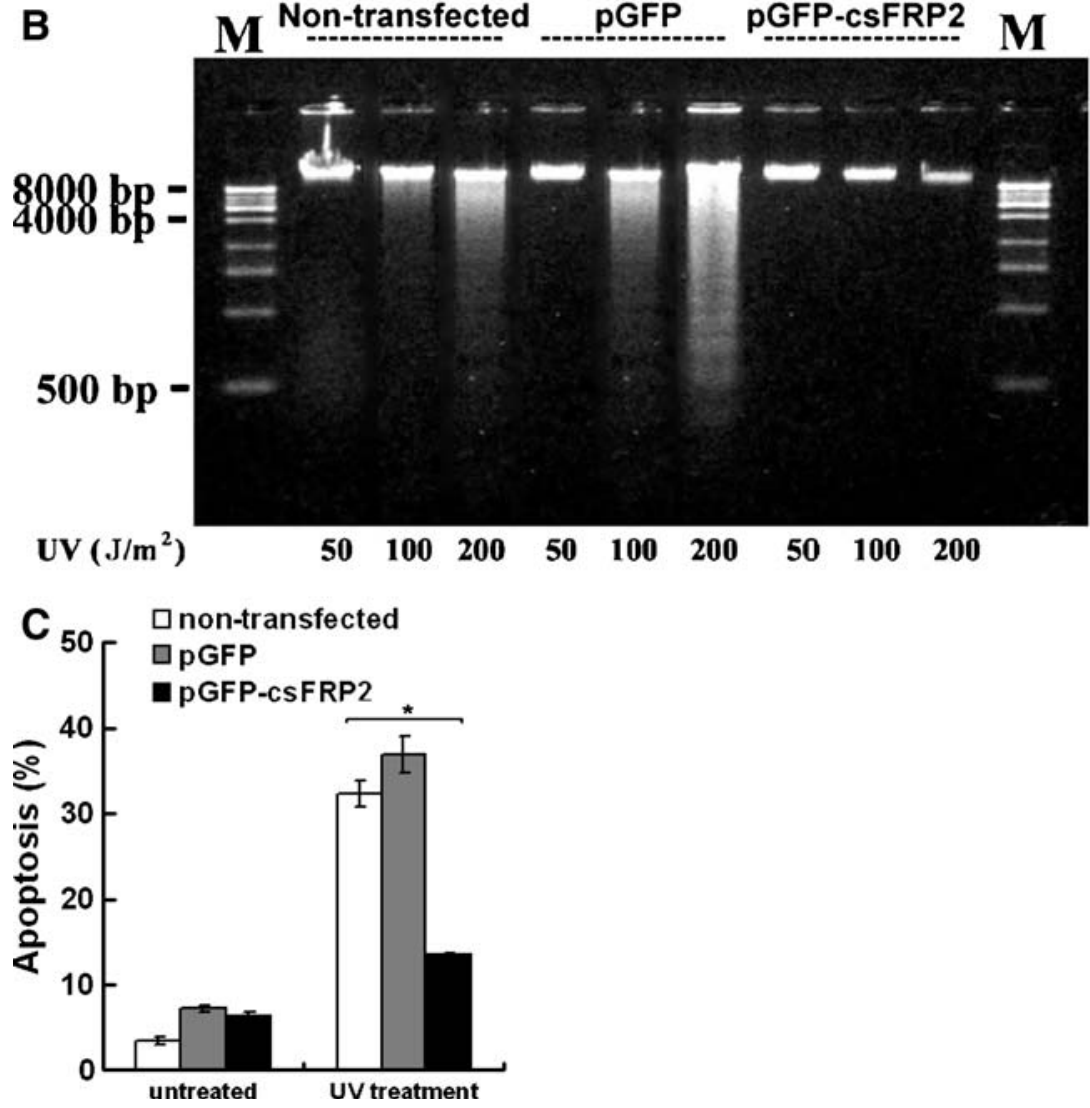

expression of sFRP2 in MPG cells could inhibit the DNA fragmentation caused by UV. The percentage of TUNELpositive cells was also decreased in the presence of sFRP2 (Fig. 1C). Taken together, these results demonstrate that canine sFRP2 has anti-apoptosis activity in the canine mammary cancer cells.
Comparison of expression between fibronectin and sFRP2 in MGTs

To determine sFRP2 expression in MGTs, we performed immunofluorescence staining in comparison with fibronectin (FN). Nucleus was stained with DAPI (blue; 
Fig. 2A-a, d). The expression of fibronectin was found in the extracellular matrix (red, Fig. 2A-b, e). Interestingly, the same regions were also stained with sFRP2 antibodies (green, Fig. 2A-c, f). The data suggest that sFRP2 and fibronectin could be co-localized in extracellular matrix of MGTs. In our previous studies, we have demonstrated that SFRP2 was associated with fibronectin by co-immunoprecipitation [18]. In other studies, binding of the SH3 domain of p130cas to prolinerich region 1 in FAK was found to be required for prevention of apoptosis on fibronectin following serum withdrawal [31]. Therefore, we tried to evaluate the tyrosine phosphorylation status of FAK. When excess fibronectin was added to MPG cells harboring the sFRP2 expression vector, the tyrosine phosphorylation of FAK was enhanced (Fig. 3), reaching peak at 10-20 min. Furthermore, we also investigated that the presence of sFRP2 could enhance the formation of fibronectin-integrin receptor complexes by immunoprecipitation and adhesion assay [18].

The possible downstream signaling pathway of the sFRP2-fibronectin interaction

The mechanism by which sFRP2 contributes to antiapoptosis is still unclear. To delineate the anti-apoptotic signaling pathways mediated by sFRP2, we attempted to examine the expression of a few related signaling factors. To delineate the anti-apoptotic signaling pathways mediated by sFRP2, we attempted to examine the expression of some signaling factors. Since focal adhesion kinase (FAK) is a key mediator of integrin signaling, we evaluated the tyrosine phosphorylation status of FAK. When MPG cells harboring the sFRP2 expression vector were allowed to survive upon UV-irradiation, the tyrosine phosphorylation of FAK was enhanced (Fig. 4A). Cleaved side products of FAK were observed under UV-induced condition, consistent with previous report [27]. The JNK suppression and NF-kB activation are implicated in the FAK-induced resistance to apoptosis [31, 32]. Therefore, these two additional apoptotic effectors, JNK and NF-kB, were also analyzed. Figure 4B shows that JNK could be activated by UV-irradiation in the control cell line, whereas it was down-regulated in the sFRP2-overexpressed cells. We have provided evidence that expression of SFRP2 could protect cell from UV-induced apoptosis and that SFRP2 interacts with FN. To examine whether sFRP2's interaction with FN is essential to activate FAK but suppress JNK activity, we used inhibitors to interrupt the interaction between sFRP2 and fibronectin. Heparin has been reported to be able to release Frizzled-related protein (FRP) from the cell surface [18]. As shown in Fig. 5A and B, in the absence of soluble heparin, sFRP2 activated FAK but suppressed JNK activity. Conversely, in the presence of soluble heparin $(0.1 \mathrm{mg} /$ $\mathrm{ml})$, the effect of sFRP2 was abolished. The other reagent, anti-integrin $\alpha 5 \beta 1$ antibody, was used to block the interaction between fibronectin and integrin $\alpha 5 \beta 1$. As shown in Fig. 5A and B, the level of FAK activation and JNK suppression was decreased. Taken together, by using the inhibitors of sFRP2-fibronectin-integrin pathway, the results showed that SFRP2- fibronectin interaction is required to activate FAK but suppress JNK activity. The role of NF$\mathrm{kB}$ in the transmission of SFRP2 anti-apoptotic signal was established by determining the level of active NF-kB in UV-treated mammary cancer cells by EMSA (Fig. 6). The active NF-kB in UV-treated cells (Fig. 6, lane 1,3) was markedly enhanced in comparison to control cells. Although the basal level of NF-kB activation was similar, the UV-induced level of active NF-kB in MPG cells expressing sFRP2 was significantly greater than that in control cells after being characterized by supershift assay with anti-p50 (lanes 2 and 4) antibodies. The DNA-binding activity of NF-kB was significantly affected by SFRP2, suggesting that sFRP2-mediated anti-apoptotic function indeed involved NF-kB activation.

\section{Discussion}

Apoptosis is an important feature of many epithelial tissues with a high turnover and serves to balance accurately the rate of new cell production. Death by apoptosis eliminates specific cells without extensive tissue damage, playing a pivotal role during tissue regeneration and the elimination of tumor cells. The process of apoptosis is integral to normal mammary gland development [33]. Thus the mammary gland is an excellent model for studying normal morphologic development and the early steps of tumor formation [33-34]. However, our understanding of the regulation of programmed cell death in health and disease is far from complete, and the challenge of converting that understanding into new therapeutic modalities has only begun to approach.

Estrogen is essential in mammary development and plays a central role in carcinogenesis of the breast [35]. The majority of human breast tumors is estrogen receptor (ER) $\alpha$-positive and respond to anti-hormone therapy. However, most malignant tumors are ER $\alpha$-negative [36]. The current therapeutic approach with antihormones, targeted at hormone receptors, is effective only in a fraction of breast cancer patients. All estrogen receptor negative (ER-) and also a fraction of ER positive (ER+) tumors do not respond to antihormone treatment [37-38]. Thus, alternative treatment protocols aimed at different targets for these classes of antihormone nonresponsive breast cancers need to be explored. Consistent with this finding, we also investigated that MPG cells derived from canine malignant MGT were 
Fig. 2 Immunoreactivity

analysis of csFRP2 expression.

(A) Immunofluorescence analysis of sFRP2. The section of canine MGT was doublelabeled with antibodies specific for fibronectin (red; b, e) and for sFRP2 (green; c, f). Nucleus was stained with DAPI (blue; a, d). (A-A) Combination with a, b, c. (A-B) Combination with e, f. Original magnification: left panel, X200; right panel, X400. (B) Immunohistochemical analysis of sFRP2. Negative control, representation of negative staining of tumor tissues with the second antibody alone. FN: Fibronectin; F2: sFRP2; CON: Negative control. Original magnification:X400

\section{A}
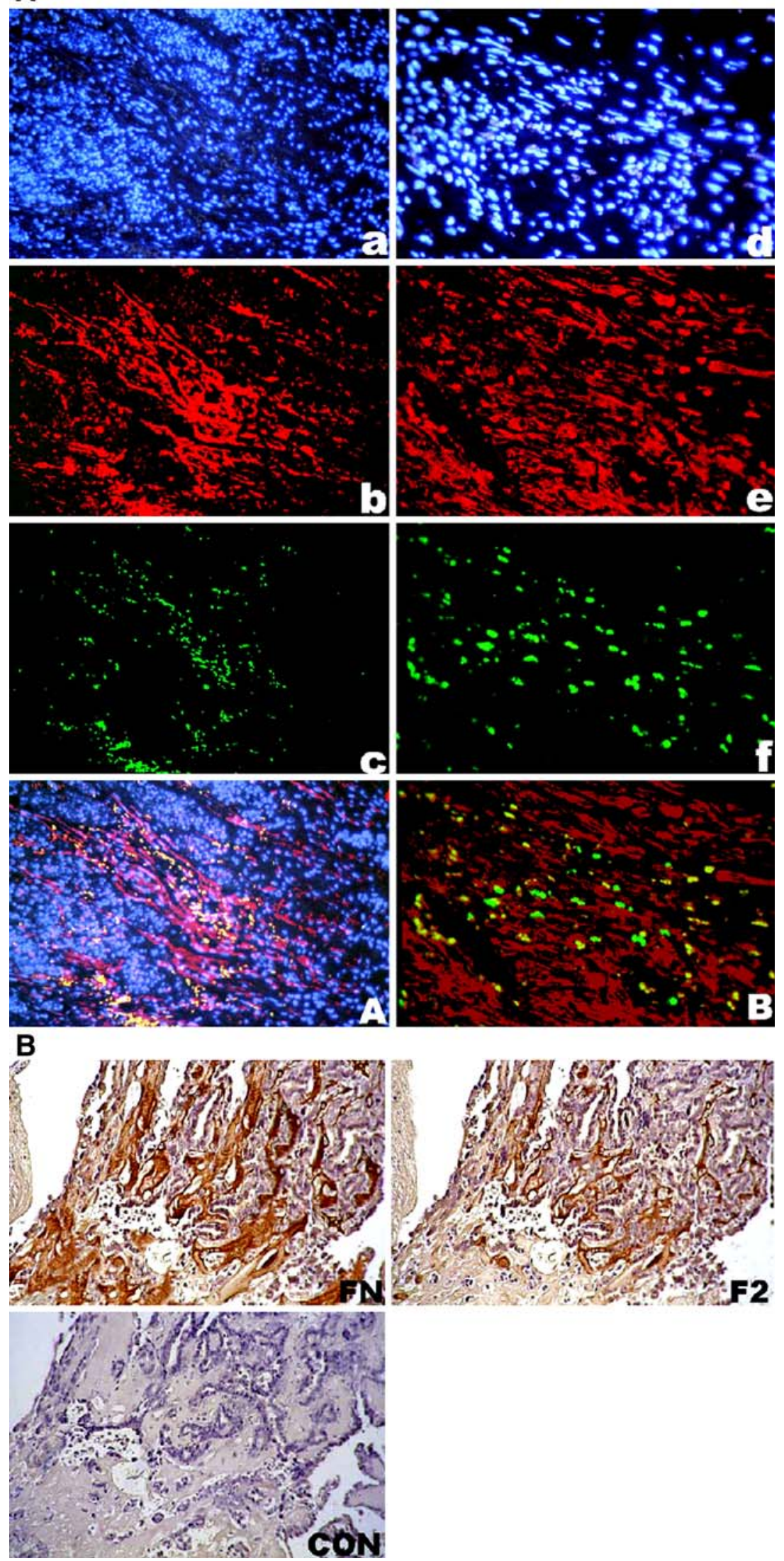

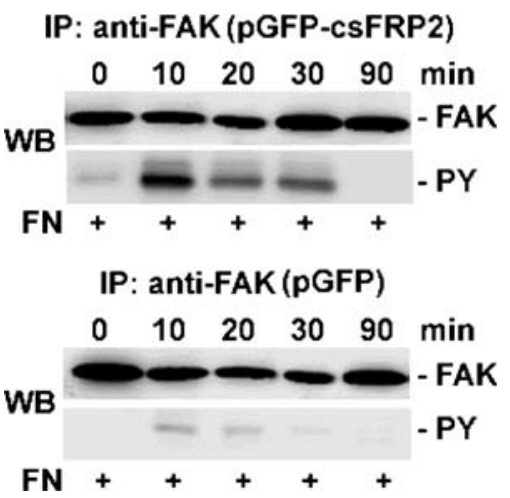

Fig. 3 sFRP2 modulated the activation of FAK. Both MPG/ pcDNA4-pGFP (bottom) and MPG/pcDNA4-pGFP-csFRP2 (top) cells (The same cells as in Fig. 1-A) were treated with fibronectin $(10 \mathrm{ng} / \mu \mathrm{l})$ for the indicated times, and whole cell extracts were subsequently prepared. FAK and FAK tyrosine phophorylation were detected by immunoprecipitation with anti-FAK antibody as indicated, followed by western blot analysis using anti-FAK antibody and antibody to phosphotyrosine

ER $\alpha$-negative [39]. Additionally, the potent mitogenic effect of Wnt-1 on mammary epithelial cells may not depend upon other mammogenic hormones either [40-41]. In a
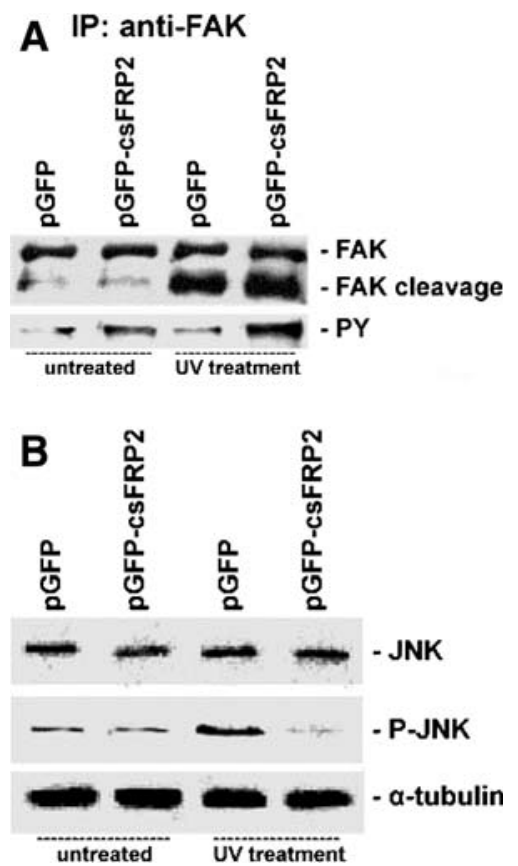

Fig. 4 SFRP2 activates FAK but suppresses JNK activity. (A) Immunoprecipitation of the FAK proteins. Both MPG/ pcDNA4pGFP and MPG/ pcDNA4-pGFP-csFRP2 cells (The same cells as in Fig. 1-A) were irradiated with or without UV at $200 \mathrm{~J} / \mathrm{m}^{2}$. After $24 \mathrm{~h}$ of incubation, the cells were lysed and FAK, FAK cleavage, and FAK tyrosine phophorylation were detected by immunoprecipitation with anti-FAK antibody as indicated, followed by western blot analysis using anti-FAK antibody and antibody to phosphotyrosine, as indicated. (B) Expression of t JNK and phospho-JNK proteins were determined by Western blot analysis. $\alpha$-tubulin was used as internal control
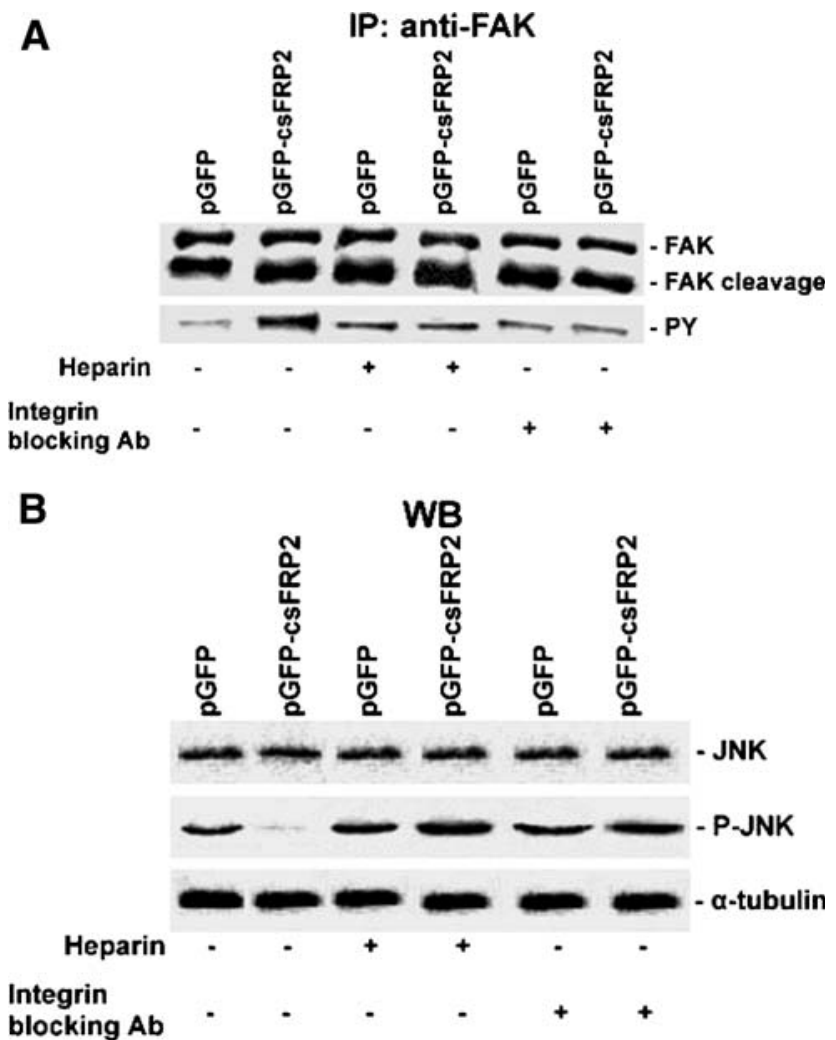

Fig. 5 SFRP2-FN-integrin $\alpha 5 \beta 1$ interaction is required to activate FAK but suppress JNK activity. The experiments were the same as Fig. 4. The FAK activity (A), and JNK phosphorylation (B) were analyzed by Western blotting in the pretreatment of heparin $(0.1 \mathrm{mg} /$ $\mathrm{ml})$ or anti-integrin $\alpha 5 \beta 1$ antibody $(0.1 \mathrm{mg} / \mathrm{ml})$

similar manner, we suggest that SFRP2 contributed to canine MGT may not depend upon mammogenic hormones. Moreover, MPG cells can serve as a good model for research on antihormone nonresponsive breast cancers.

The level of NF-kB has been shown to be elevated in ER- human breast cancers, as compared with ER+ cells [42-46]. The role of NF-kB in tumorigenesis is circumstantial, such as higher levels of activated NF-kB in ERtumor cells. In recent studies, it has demonstrated the antitumorigenic activity of a compound that inhibits activation of NF-kB without causing significant detectable cellular damage of vital organs in a model of mouse tumor [47]. Furthermore, selective activation of NF-kB induced loss of tumorigenic potential of the parent CSMLO cells, thus strongly suggesting a role of this transcription factor in ERmammary epithelial cell carcinogenesis [47]. NF-kB exits in an inactive state in most cell types, except B lymphocytes [48]. Interestingly, MPG cells isolated from our lab had basal expression level of NF-kB, suggesting that NF-kB may play a role in canine MGTs. Moreover, numerous tumor cells with elevated levels of NF-kB are resistant to apoptosis induced by chemotherapy [49], radiotherapy [50], and $\mathrm{TNF} \alpha$ treatment [50-52]. Therefore, inhibition of 


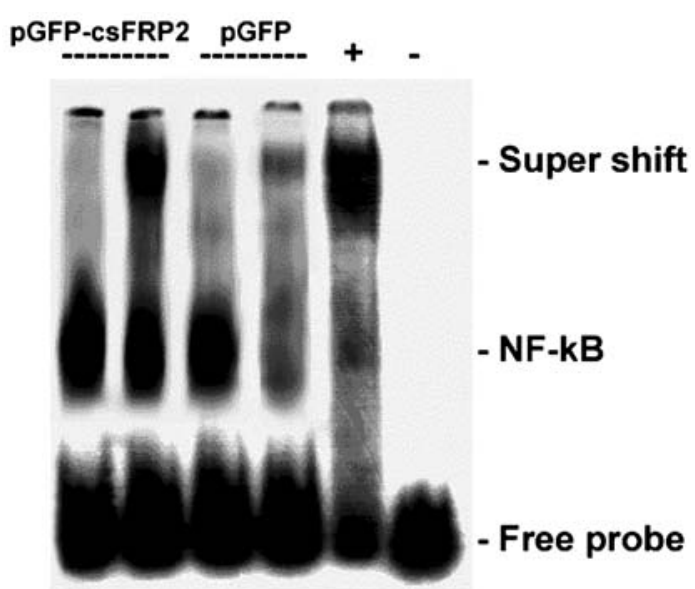

Fig. 6 Active NF-kB complex in MPG cells expressing SFRP2. Both MPG/ pcDNA4-pGFP and MPG/ pcDNA4-pGFP-cSFRP2 cells (The same cells as in Fig. 1-A) were irradiated with UV at $200 \mathrm{~J} / \mathrm{m}^{2}$. After $30 \mathrm{~min}$ of incubation, nuclear extracts from control and UV-treated cells were incubated in a standard EMSA reaction mixture containing $\left[{ }^{32} \mathrm{P}\right]$-labeled double-stranded oligonucleotide. The NF-kB- $\left[{ }^{32} \mathrm{P}\right]$ DNA complex was characterized by supershift assay with anti-p50 (lanes 2 and 4) antibodies. Nuclear extracts were incubated with antip50 antibodies for $15 \mathrm{~min}$ at room temperature, followed by incubation for an additional $30 \mathrm{~min}$ in the presence of $\left[{ }^{32} \mathrm{P}\right]$ doublestranded NF-kB oligonucleotide, and subjected to EMSA as described. The supershifted complexes are as indicated in the autoradiograph

NF-kB would be a likely approach to enhance anti-tumor therapy in tumors with constitutive NF-kB activity.

Understanding of mechanisms implicated in the apoptosis control by NF-kB may lead to the development of new strategies to improve cancer therapy. Although several genes that may play a role in blocking apoptosis and whose expression is regulated by NF-kB, the precise understanding of the role of NF-kB in controlling apoptosis is still lacking. There are two general models about Wnt-frizzled signaling by which NF-kB transcription factors may regulate apoptosis: (1) The SFRP2(Wnt $\leftrightarrow$ Frizzled $\rightarrow$ Dishevelled $\rightarrow$ GSK- $3 \beta \rightarrow \beta$-catenin-Tcf complex pathways can result in activation of NF-kB. sFRP-2 is a modulator of Wnt signaling [11]. Wnt-1 acts as a survival factor in PC12 cells by activating the death-suppressing transcription factor NF-kB and by inhibiting the apoptosis induced by serum withdrawal through a pathway that is partially independent of PI-3 kinase, but is dependent on the inactivation of GSK-3 $\beta$ [53-54]. Moreover, overexpression of transfected sFRP2 in breast adenocarcinoma cells increases their resistance to apoptotic signals, associated with increased intracellular levels of $\beta$-catenin [17]. Consistent with this finding, we have demonstrated that MPG cells expressing sFRP2 could inhibit apoptosis, associated with enhanced expression of $\beta$-catenin. (2) The fibronectin $\rightarrow$ integrin receptor $\rightarrow$ FAK $\rightarrow$ PI-3K $\rightarrow$ Akt pathways appear to cooperate for activation of NF-kB by phosphorylating different activating residues on IKK $\alpha$. In our previous studies, it was found that the presence of sFRP2 could enhance the formation of fibronectin-integrin receptor complexes. One of ECM components, fibronectin, is particularly effective in providing survival signals for several cell types, and that these survival signals are transduced by FAK [55-57]. Additionally, PI-3K-Akt survival pathway and NF-kB activation are involved in the FAK-induced resistance to apoptosis [32]. In this study, we show that SFRP2 can inhibit apoptosis, associated with increased FAK and NF-kB activities.

Several lines of evidences suggest that JNK plays an important role in tumor cells. Ras-induced tumorigenicity is suppressed by mutation of the JNK phosphorylation sites on c-Jun [57]. These data strongly support the hypothesis that JNK is relevant to cancer. The JNK pathway has been implicated in both apoptosis and survival signaling [58]. Although one function of JNK is implicated in cancer, the mechanism of JNK action is unclear. During tumor development, it is likely that JNK-dependent stress-induced apoptosis must be suppressed. This would imply that components of the JNK pathway are potential tumor suppressor genes. Established tumor cells must adopt mechanisms to inhibit JNK-dependent apoptosis. In this study, we also demonstrated that MPG cells expressing sFRP2 inhibited apoptosis via JNK suppression. Recent investigations using anti-sense JNK oligonucleotides support the conclusion that JNK functions are distinct between normal and tumor cells. These studies imply that JNK inhibition may be useful for tumor therapy. Furthermore, these studies indicate that genetic interactions with cancerassociated genes may be critical for determining the outcome of JNK signaling.

In mammals, aberrant regulation of the Wnt pathway is implicated in tumorigenesis [4]. The precise mechanism by which Wnt signaling 'switches' between the canonical Wingless/Wnt pathway or activation of the JNK pathway is unclear; however, recent evidence implicates the proteins Dishevelled and PAR-1. [59-60]. Dishevelled under enhancing Wnt pathway can activate JNK, whereas PAR-1 decreases JNK activity. Wnt signaling increases endogenous PAR-1 kinase activity and subsequently potentiates the canonical Wnt pathway at a level upstream of Axin and $\beta$-catenin. In contrast, activation of PAR-1 inhibits Dishevelled-mediated JNK activation [60]. Thus, PAR-1 is a positive regulator of the $\mathrm{Wnt} / \beta$-catenin pathway and an inhibitor of the JNK pathway. Consistent with this idea, we found that MPG cells expressing sFRP2 enhanced the expression of $\beta$-catenin and inhibited apoptosis via JNK suppression. Therefore, we suggest that PAR-1 might play an important role in MPG cells, associated anti-apoptotic function. The detailed mechanism underlying the sFRP2mediated signaling is a critical subject of future research. 


\section{References}

1. Hanahan D, Weinberg RA (2000) The hallmarks of cancer. Cell 100:57-70

2. Kumar R, Vadlamudi RK, Adam L (2000) Apoptosis in mammary gland and cancer. Endocr relat cancer 7:257-269

3. Dale TC (1998) Signal transduction by the Wnt family of ligands. Biochem J 329:209-223

4. Polakis P (2000) Wnt signaling and cancer. Genes Dev 14:18371851

5. Ellies DL, Church V, Francis-West P, Lumsden A (2000) The WNT antagonist cSFRP2 modulates programmed cell death in the developing hindbrain. Development 127:5285-5295

6. Nusse R, Varmus HE (1982) Many tumors induced by the mouse mammary tumor virus contain a provirus integrated in the same region of the host genome. Cell 31:99-109

7. Cadigan KM, Nusse R (1997) Wnt signaling: a common theme in animal development. Genes Dev 11:3286-3305

8. Nusse R, Varmus HE (1992) Wnt genes. Cell 69:1073-1087

9. Bergstein I, Brown AMC (1999) Breast cancer: molecular genetics, pathogenesis and therapeutics. In: Bow-cock AM (ed) Human Press, Totowa, New Jersey, pp 181-198

10. Wang S, Krinks M, Lin K, Luyten FP, Moos M Jr (1997) Frzb, a secreted protein expressed in the Spemann Organizer, binds and inhibits Wnt-8. Cell 88:757-766

11. Finch PW, He X, Kelley MJ, Üren A, Schaudies RP, Popescu NC, Rudikoff S, Aaronson SA, Varmus HE, Rubin JS (1997) Purification and molecular cloning of a secreted, frizzled-related antagonist of Wnt action. Proc Natl Acad Sci USA 94:67706775

12. Rattner A., Hsieh JC, Smallwood PM, Gilbert DJ, Copeland NG, Jenkins NA, Nathans J (1997) A family of secreted proteins contains homology to the cysteine-rich ligand-binding domain of frizzled receptors. Proc Natl Acad Sci USA 94:2859-2863

13. Wolf V, Ke G, Dharmarajan AM, Bielke W, Artuso L, Saurer S, Friis R (1997) DDC-4, an apoptosis associated gene, is a secreted frizzled relative. FEBS Lett 417:385-389

14. Jones SE, Jomary C (2002) Secreted frizzled-related proteins: searching for relationships and patterns. BioEssays 24:811-820

15. Leimeister C, Bach A, Gessler M (1998) Developmental expression patterns of mouse sFRP genes encoding members of the secreted frizzled related protein family. Mech Dev 75:29-42

16. Ladher RK, Church VL, Allen S, Robson L, Abdelfattah A, Brown NA, Hattersley G, Rosen V, Luyten FP, Dale L, FrancisWest PH (2000) Cloning and expression of the Wnt antagonists SFRP-2 and Frzb during chick development. Dev Biol 218:183198

17. Melkonyan HS, Chang WC, Shapiro JP, Mahedevappa M, Fitzpatrick PA, Kiefer MC, Tomei LD, Urmansky SR (1997) SARPs: A family of secreted apoptosis-related proteins. Proc Nat Acad Sci USA 94:13636-13641

18. Lee JL, Lin CT, Chueh LL, Chang CJ (2004) Autocrine/paracrine secreted Frizzled-related protein 2 induces cellular resistance to apoptosis: a possible mechanism of mammary tumorigenesis. J Biol Chem 279: 14602-14609

19. Schumann H, Holtz J, Zerkowski HR, Hatzfeld M (2000) Expression of secreted frizzled related proteins 3 and 4 in human ventricular myocardium correlates with apoptosis related gene expression. Cardiovasc Res 45:720-728

20. Jones SE, Jomary C, Grist J, Stewart HJ, Neal MJ (2000) Altered expression of secreted Frizzled-related protein-2 in retinitis pigmentosa retinas. Invest Ophthalmol Vis Sci 41:1297-1301

21. Jones SE, Jomary C, Grist J, Stewart HJ, Neal MJ (2000) Modulated expression of secreted frizzled-related proteins in human retinal degeneration. NeuroReport 11:3963-3967
22. Lee JL, Chang CJ, Wu SY, Sargan DR, Lin CT (2004) Secreted frizzled-related protein 2 (SFRP2) is highly expressed in canine mammary gland tumors but not in normal mammary glands. Breast Cancer Res Treat 84: 139-149

23. Miller JR, Hocking AM, Brown JD, Moon RT (1999) Mechanism and function of signal transduction by the $\mathrm{WNT} / \beta$-catenin and WNT/Ca ${ }^{2+}$ pathways. Oncogene 18:7860-7872

24. Lee JL, Chang CJ, Chueh LL, Lin CT (2003) Expression of secreted frizzled-related protein 2 in a primary canine mammary tumor cell line: a candidate tumor marker for mammary tumor cells. In Vitro Cell Dev Biol Anim 39: 221-227

25. Lin CT, Sargan DR (1997) A method for generating subtractive cDNA libraries retaining clones containing repetitive elements. Nucleic Acids Res 25:4427-4428

26. Lin CT, Sargan DR (2001) Generation and analysis of canine retinal ESTs: Isolation and expression of retina-specific gene transcripts. Biochem Biophys Res Commun 282:394-403

27. Chan PC, Lai JF, Cheng CH, Tang MJ, Chiu CC, Chen HC (1999) Suppression of ultraviolet irradiation-induced apoptosis by overexpression of focal adhesion kinase in Madin-Darby canine kidney cells. J Biol Chem 274:26901-26906

28. Ruest LB, Marcotte R, Wang E (2002) Peptide elongation factor eEF1A-2/S1 expression in cultured differentiated myotubes and its protective effect against caspase-3-mediated apoptosis. J Biol Chem 277:5418-5425

29. Chang CJ, Chen YL, Lee SC (1998) Coactivator TIF1beta interacts with transcription factor C/EBPbeta and glucocorticoid receptor to induce alpha1-acid glycoprotein gene expression. Mol Cell Biol 18:5880-5887

30. Lin WC, Shen BJ, Tsay YG, Yen HC, Lee SC, Chang CJ (2002) Transcriptional activation of C/EBPbeta gene by c-Jun and ATF2. DNA Cell Biol 21:551-560

31. Almeida EAC, Ilic D, Han Q, Hauck CR, Jin F, Kawakatsu H, Schlaepfer DD, Damsky CH (2000) Matrix survival signaling: from fibronectin via focal adhesion kinase to c-Jun NH2-terminal kinase. J Cell Biol 149:741-754

32. Sonoda Y, Matsumoto Y, Funakoshi M, Yamamoto D, Hanks SK, Kasahara T (2000) Anti-apoptotic role of focal adhesion kinase (FAK). Induction of inhibitor-of-apoptosis proteins and apoptosis suppression by the overexpression of FAK in a human leukemia cell line, HL-60. J Biol Chem 275:16309-16315

33. Medina D (1996) The mammary gland: a unique organ for the study of development and tumorigenesis. J Mam Gland Biol Neoplasia 1:5-19

34. Yang WY, Liu CH, Chang CJ, Lee CC, Lin CT (2006) Proliferative activity, apoptosis and expression of oestrogen receptor and $\mathrm{BCl}-2$ oncoprotein in canine mammary gland tumors. J Comp Path 134:74-83

35. Pike MC, Spicer DV, Dahmoush L, Press MF (1993) Estrogens, progestogens, normal breast cell proliferation, and breast cancer risk. Epidemiol Rev 15:17-35

36. McGuire WL, Clark GM (1985) Role of progesterone receptors in breast cancer. Semin Oncol 12:12-16

37. Jordan VC (1995) Third annual William L. McGuire Memorial Lecture. "Studies on the estrogen receptor in breast cancer' 20 years as a target for the treatment and prevention of cancer. Breast Cancer Res Treat 36:267-285

38. Hedden A, Muller V, Jensen EV (1995) A new interpretation of antiestrogen action. Ann NY Acad Sci 761:109-120

39. Yang WY, Liu CH, Chang CJ, Lee CC, Chang KJ, Lin CT (2006) Proliferative activity, apoptosis and expression of oestrogen receptor and bcl-2 oncoprotein in canine mammary gland tumours. J Comp Pathol 134:74-83

40. Edwards PA, Hiby SE, Papkoff J, Bradbury JM (1992) Hyperplasia of mouse mammary epithelium induced by expression of 
the Wnt-1 (int-1) oncogene in reconstituted mammary gland. Oncogene 7:2041-2051

41. Lin TP, Guzman RC, Osborn RC, Thordarson G, Nandi S (1992) Role of endocrine, autocrine, and paracrine interactions in the development of mammary hyperplasia in Wnt-1 transgenic mice. Cancer Res 52:4413-4419

42. Nakshatri H, Bhat-Nakshatri P, Martin DA, Goulet RJ Jr, Sledge GW Jr (1997) Constitutive activation of NF-kappaB during progression of breast cancer to hormone-independent growth. Mol Cell Biol 17:3629-3639

43. Bhat-Nakshatri P, Newton TR, Goulet R Jr, Nakshatri $H$ (1998) NF-kappaB activation and interleukin 6 production in fibroblasts by estrogen receptor-negative breast cancer cell-derived interleukin 1alpha. Proc Natl Acad Sci USA 95:69716976

44. Sovak MA, Bellas RE, Kim DW, Zaneiski GJ, Rogers AE, Traish AM, Sonenshein GE (1997) Aberrant nuclear factor-kappaB/Rel expression and the pathogenesis of breast cancer. J Clin Invest 100:2952-2960

45. Rayet B, Gelinas C (1999) Aberrant Rel/NF-kB genes and activity in human cancer. Oncogene 18:6938-6947

46. Biswas DK, Cruz AP, Gansberger E, Pardee AB (2000) Epidermal growth factor-induced nuclear factor kappa B activation: A major pathway of cell-cycle progression in estrogen-receptor negative breast cancer cells. Proc Natl Acad Sci USA 97:85428547

47. Biswas DK, Dai SC, Cruz A, Weiser B, Graner E, Pardee AB (2001) The nuclear factor kappa B (NF-kB): A potential therapeutic target for estrogen receptor negative breast cancers. Proc Natl Acad Sci USA 98:10386-1039

48. Sen R, Baltimore D (1986) Multiple nuclear factors interact with the immunoglobulin enhancer sequences. Cell 46:705-716

49. Wang CY, Mayo MW, Baldwin Jr AS (1996) TNF- and cancer therapy-induced apoptosis: potentiation by inhibition of NFkappaB. Science 274:784-787
50. Liu ZG, Hsu H, Goeddel DV, Karin M (1996). Dissection of TNF receptor 1 effector functions: JNK activation is not linked to apoptosis while NF-kappaB activation prevents cell death. Cell 87:565-575

51. Van Antwerp DJ, Martin SJ, Kafri T, Green DR, Verma IM (1996) Suppression of TNF-alpha-induced apoptosis by NFkappaB. Science 274:787-789

52. Hoeflich KP, Luo J, Rubie EA, Tsao MS, Jin O, Woodgett JR (2000) Requirement for glycogen synthase kinase-3b in cell survival and NF-kB activation. Nature 406:86-90

53. Bournat JC, Brown AMC, Soler AP (2000) Wnt-1 dependent activation of the survival factor NF-kB in PC12 cells. J Neurosci Res 61:21-32

54. Frisch SM, Vuori K, Ruoslahti E, Chan-Hui PY (1996) Control of adhesion-dependent cell survival by focal adhesion kinase. J Cell Biol 134:793-799

55. Hungerford JE, Compton MT, Matter ML, Hoffstrom BG, Otey CA (1996) Inhibition of pp125FAK in cultured fibroblasts results in apoptosis. J Cell Biol 135:1383-1390

56. Ilic D, Almeida EA, Schlaepfer DD, Dazin P, Aizawa S, Damsky $\mathrm{CH}$ (1998) Extracellular matrix survival signals transduced by focal adhesion kinase suppress p53-mediated apoptosis. J Cell Biol 143:547-560

57. Behrens A, Jochum W, Sibilia M, Wagner EF (2000) Oncogenic transformation by ras and fos is mediated by c-Jun N-terminal phosphorylation. Oncogene 19:2657-2663

58. Ip YT, Davis RJ (1998) Signal transduction by the c-Jun Nterminal kinase (JNK) - from inflammation to development. Curr Opin Cell Biol 10:205-219

59. Boutros M, Paricio N, Strutt DI, Mlodzik M (1998) Dishevelled activates JNK and discriminates between JNK pathways in planar polarity and wingless signaling. Cell 94:109-118

60. Sun TQ, Lu B, Feng JJ, Reinhard C, Jan YN, Fantl WJ, Williams LT (2001) PAR-1 is a Dishevelled-associated kinase and a positive regulator of Wnt signalling. Nat Cell Biol 3:628-636 